\title{
The effect of manufacturing agility competencies on lean manufacturing in increasing operational performance
}

\author{
Budianto $^{a^{*}}$, Surachman ${ }^{a}$, Djumilah Hadiwidjojo a and Rofiaty ${ }^{a}$
}

\begin{tabular}{l}
${ }^{a}$ Departement of Management, Facu \\
\hline C H R O N I C L E \\
\hline Article history: \\
Received August 15, 2020 \\
Received in revised format \\
September 8, 2020 \\
Accepted October 92020 \\
Available online \\
October 92020 \\
\hline Keywords: \\
Lean manufacturing (LM) \\
Manufacturing Agility \\
Competencies (MAC) \\
Operational performance \\
(OP) \\
\hline
\end{tabular}
\begin{abstract}
A B S T R A C T
This study aims to assess the success of implementing Lean Manufacturing (LM) practices in food companies in Indonesia through the mediating role of Manufacturing Agility Competencies (MAC) to improve Operational Performance (OP). The method used is survey method. The study uses a positivist paradigm to see the effect of Lean manufacturing on operational performance. Testing used Structural Equation Modeling (SEM) by the Partial Least Square (PLS) approach. Finding of this study reveals that lean manufacturing practices have no positive effect on operational performance in Indonesian food industries. Meanwhile, the mediating role of Manufacturing Agility Competencies has succeeded in increasing the effect of Lean Manufacturing on operational performance. The originality of the research lies in the process of forming Manufacturing Agility Competencies as a strategy with a long process based on the experiences and observations made in food companies in Indonesia.
\end{abstract}

(C) 2021 by the authors; license Growing Science, Canada.

\section{Introduction}

The current industrial development forces a production process to be more effective, efficient, precise and streamlined. The production process is the concept of Lean Manufacturing (LM) which continues to develop and evolve so that it can be widely accepted (Spear et al., 1999). This concept is inspired by the success of the Toyota Production System (TPS) which was introduced as a strategy (Womack et al., 1994). The modern LM concept originated from the Toyota Production System (TPS) pioneered by Ohno and Singo (Sugimori et al., 1977). The success of LM has been felt by many nonprocessing manufacturing companies. The success of LM has not been widely felt by the processing industry. This industry has greater complexity due to product characteristics, process methods, product variants etc. The difference in complexity will make LM practices adaptable and evolve so that LM can be applied in all industrial sectors. The practice of LM has succeeded in providing a direct positive impact on Operational Performance (OP) as has been proven by several previous researchers. On the other hand, there are several studies that give different results. LM practices do not have a direct positive effect on performance so that other variables need to be mediated. Some researchers try to make efforts to improve performance through several mediations. Mediation and research pioneers so far include Core Competencies (Gilgeous \& Parveen, 2001), Agile Manufacturing (AM) (Gunasekaran, 1998), Human Resource Management (Osterman \& Paul, 1994), and Skills, technology and knowledge (Wernerfelt, 1984). The mediation efforts carried out so far have produced inconsistent results. Referring to previous literature, mediation efforts are only carried out through the theoretical approach of The Resource Based View (RBV) and strategic management. RBV can be seen from the Core Competencies (CC) which includes Human Resource Management and Skills, Technology, Knowledge. Meanwhile, AM is reflected in the nature of strategic management. The two theories mediate with their pure character without any elaboration process. This study offers an elaborate nature of the two theories for the mediation process.

\footnotetext{
* Corresponding author

E-mail address: budianto delta@yahoo.com (Budianto)

(C) 2021 by the authors; licensee Growing Science. doi: $10.5267 /$ j.uscm. 2020.10 .001
} 
The various complexities in the food industry must be able to respond to changing customer desires. The use of RBV must be able to overcome the complexity that occurs (Mahoney \& Pandian, 1992) and there is a need for a strategy to respond to the speed of changing customer desires. This study pays great attention to the failure of LM practices against OP in the food industry, and attempts to offer elaborate mediating variables on the nature of CC and AM. Efforts in the elaboration process carried out are: first, finding, filtering and evaluating competencies to become CC (Prahalad \& Hamel, 1990) in overcoming the extraordinary complexity in the food industry (Cox \& Chicksand, 2005); second, making and evaluating AM activities that have the ability to be agile and flexible (Gunasekaran, 1999) to respond to market changes, changes in customer loyalty with tireless innovation and continuous improvement processes; third, discussing points a and b by forming a Focus Group Discussion (FGD) involving several food company groups. Practicing direct CC and AM activities in the elaboration process, evaluating the effectiveness of elaboration (Danilovic \& Leisner, 2007; Sud-on et al., 2014); fourth, the last process is to determine an effective elaboration process then realize it in manufacturing activities (Danilovic \& Leisner, 2007) and make continuous improvements.

Based on the aforementioned series of mediation formation processes, the researcher attempts to close the research gap so far by creating a Manufacturing Agility Competencies (MAC) variable to mediate the relationship between LM and OP in the food industry.

\section{Research Background}

\section{Lean Manufacturing}

The lean concept was pioneered by Ohno (1978) in the Toyota Total Production System in the form of Just In Time (JIT) practice and the Kanban System (Sugimori et al., 1977). This concept was first introduced by Krafcik (1988) in his work "Trumph of Lean Production System" which defines LM as a production process that utilizes fewer resources in its use. Furthermore Womack et al. (1990) describe LM as a dynamic change process that is driven by a series of principles and best practices systematically to improve continuous improvement. Maximum efficiency is achieved by eliminating the causes of process inflexibility, resulting in quality and cost per unit of process. LM is an integrated technical tool to minimize both internal and external variability (Shah \& Ward, 2003). The effectiveness of LM is always associated with operational performance (Jabbour et al., 2013) in increasing labor productivity, quality, waiting time, cycle time and manufacturing costs. LM is also known as lean production, which is one of the most popular paradigms of reducing waste in the manufacturing and service industries in Indonesia. Dora and Gellynck (2015) create a framework for implementing LM in the food industry because the role of LM in the food industry has not been clearly seen. In addition, a number of studies have shown that LM is actually widely used in the process of food companies (Engelund et al., 2009), but the impact has not been much felt (Cox \& Chicksand, 2005; Zokaei \& Simons, 2006).

\section{Manufacturing Agility Competencies}

Manufacturing Agility Competencies (MAC) is a series of agile and competency based manufacturing practices. MAC practice in this study is the result of elaboration between the nature of AM and CC through Focus Group Discussion (FGD) of several food companies in Indonesia in an effort to get out of the extraordinary complexity. FGDs are conducted by companies to find a more effective and efficient way to deal with the very fast changing consumer desires by implementing a manufacturing strategy that can anticipate rapid changes in a very high frequency. The results of the discussion in the FGD are the raw MAC that must be selected and tested to see the results of the effectiveness of the MAC practice. The trial process involves rigorous screening and evaluation. Sometimes, multiple trials are needed over a long period of time to ensure that MAC practices are feasible to implement as an LM implementation strategy. The process of forming MAC in this study is shown in Fig. 1.

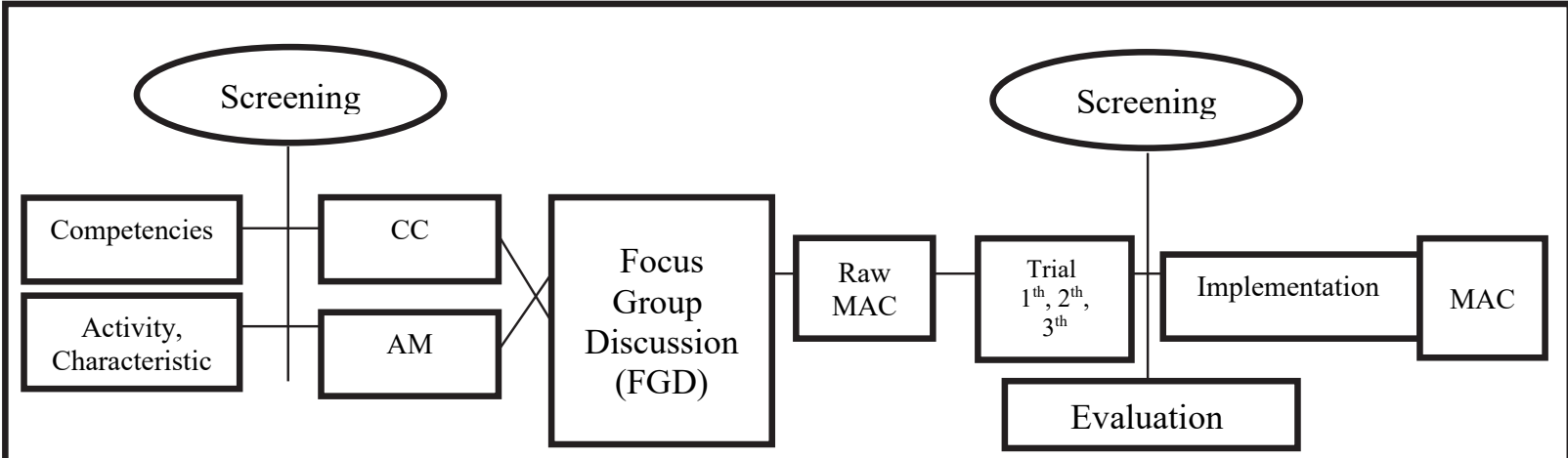

Fig. 1. MAC formation process

Fig. 1 above illustrates that the success of LM practices directly against OP is much influenced by the existing complexity. This study attempts to anticipate the complexity in the food industry by applying MAC so that LM practices are more 
focused on increasing OP. The focus of LM activities will facilitate the application of LM in the Food Industry. The failure to implement LM in Indonesian food companies is the main focus so that LM can be applied optimally by considering the complexity that becomes a disturbance in its application. The complexity that was originally a distraction must be converted into practices that support and support MAC so that LM practices can be implemented in line with the complexity in the food industry.

\section{Operational Performance}

Operational performance is considered a viable option when examining the direct effects of organizational activities. In this study, the indicators used are a reduction in reject/rework costs, efficiency of manufacturing unit costs (Uhrin et al., 2017), Manufacturing Cycle Time and reduced inventory (Wu, 2003). The selection of these indicators is based on observations in food companies in Indonesia.

\section{Research Models and Hypotheses}

The research concept framework for the relationship of the three variables is shown in Fig. 2 which refers to the existing literature, as well as an attempt to close the existing research gaps related to the relationship between LM and OP.

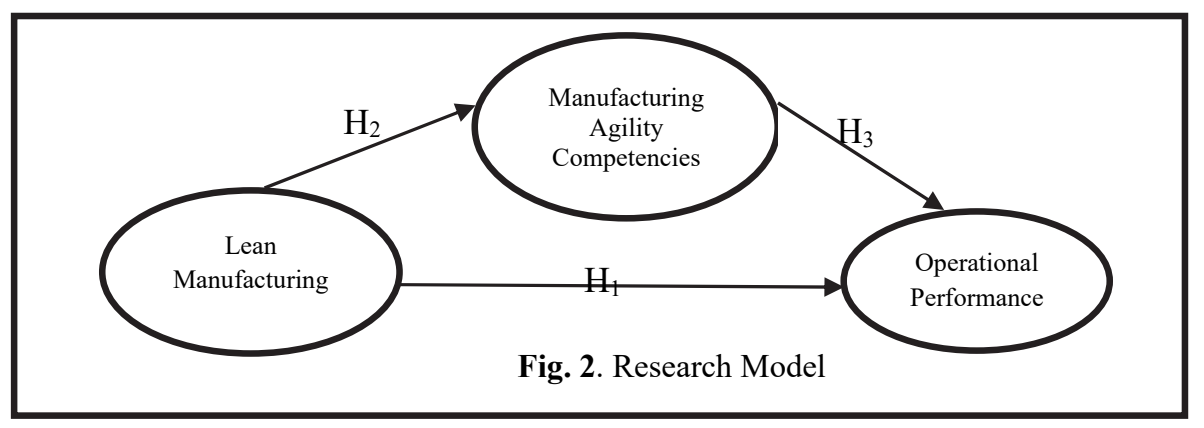

\subsection{The relationship of $L M$ and $O P$}

Moori et al. (2013) proved that the relationship between LM and OP was more significant without having to be mediated by other variables. Uhrin et al. (2017) also did the same thing by making a mediating variable for LM to OP, but the results of the study are more significant if they are not mediated or moderated. LM practices also reflect the use of TPM, TQM, and JIT practices that are widely used in the industry today. Reviewing the description above, it is necessary to hypothesize the relationship between the two variables if implemented in the Indonesian food industry. The efforts made by (Moori et al., 2013; Uhrin et al., 2017) at least provide evidence that the relationship between LM and OP has a direct effect.

The two researchers tried to adopt previous researchers by adding indicators for LM and OP. These additions follow the current development needs of the industry, such as indicators that illustrate flexibility for urgent situations or changing priorities. Referring to the description above, the hypotheses built in this study are:

$\mathbf{H}_{1}:$ LM has positive effect on $O P$.

\subsection{The relationship of $L M$ and $M A C$}

Agility Competencies are competencies that must be developed in an organization in order to have sufficient strength to respond to change. (Jin-Hai et al., 2003) succeeded in conceptualizing an AM evolution scheme that originated from the practice of LM which was sorted and analyzed into CC in companies. Then, flexibility which is the character of Agile is collaborated with CC practice to become Real Agility Manufacturing. The combination of LM, CC and flexibility characteristics is expected to be able to form a characteristic that reflects the needs of today's companies. Given the lack of manufacturing literature based on $\mathrm{CC}$ and $\mathrm{AM}$, researchers want to elaborate indicators from CC and AM to become Manufacturing Agility Competencies. The hypothesis that is built to describe the relationship between these two variables is:

$\mathbf{H}_{2}$ : LM has positive effect on $M A C$.

\subsection{The relationship of $M A C$ and $O P$}

Sud-on et al. (2014) combined capabilities which are part of CC with Agile to become Manufacturing Agility Capabilities that have a positive effect on OP in the Thai automotive industry. The role of Manufacturing Agility Capabilities is also the focus of Almahamid et al. (2010) in the role of Agility Capability which affects competitive advantage in manufacturing operations.

Based on the above literature, the research of Sud-on et al. (2014) is similar to this study in the relationship between the two variables. The similarity can be seen from how to get the Manufacturing Agility Capabilities variable so that the researcher builds a hypothesis that describes the relationship between the two variables as follows:

$\mathbf{H}_{3}$ : $M A C$ has positive effect on $O P$. 


\subsection{The relationship of $L M, O P$ and $M A C$}

The description above shows several relationships between variables, namely between LM to OP, LM to MAC and MAC to OP. The relationship between LM and OP if mediated by MAC has not been found in the previous literature. However, there is no reference to the relationship between the three variables which indicates the MAC position as the mediator. Therefore, the hypotheses built in this study are:

\section{H4: The LM relationship has positive effect on OP through MAC mediation.}

\section{Research Method}

This study examines the effect of LM on OP in the Indonesian food industry. There are 244 companies studied that have registered to LPPOM MUI. These companies are located in Jakarta, Bogor, Depok, Tangerang, Bekasi. 157 questionnaires were distributed manually to food companies in Indonesia. The distribution of questionnaires was also carried out electronically by considering the percentage of questionnaire returns. Questionnaires are also distributed via google form which are distributed via email, social media.

\subsection{Respondent Characteristics}

The desired company characteristics include the number of employees, turnover per year, number of subsidiary companies, number of certificates, product variations, product expiration period, and types of raw materials.

\subsection{Validity and reliability}

The validity test used a cross loading value $>0.6$, where the initial stage of developing a cross loading value measurement scale of 0.5 to 0.6 is considered sufficient (Chin, 1998 in Ghozali, 2011)and the Square Root of Average Variance Extracted (AVE) value is greater than 0.50 (Fornell \& Larcker, 1981 in Ghozali, 2011). Reliability test refers to the value of Cronbach's Alpha (standard > 0.6), Composite Reliability (standard $>0.7$ ).

Table 1

Validity and Reliability Test

\begin{tabular}{clcc}
\hline \multicolumn{1}{c}{ Parameter } & Standard & Result \\
\hline \multirow{3}{*}{ Kont } & Loading factor (outer loading) & $>0.6$ & $0.6-0.8$ \\
& AVE & $>0.5$ & $0.505-0.509$ \\
& Communality & $>0.5$ & $0.505-0.509$ \\
\hline \multirow{2}{*}{ Discriminant Validity } & AVE root and latent variable correlation & AVE Root $>$ Discriminant validity & AVE Root $>$ Discriminant validity \\
& Cross Loading & $>0.7$ & $>0.7$ \\
\hline \multirow{2}{*}{ Reliability } & Cronbach's Alpha & $>0.6$ & $0.77-0.86$ \\
& Composite Reliability & $>0.7$ & $0.846-0.892$ \\
\hline
\end{tabular}

\subsection{Structural Model Testing}

Testing the value of the structural path coefficient of the model is carried out using SEM PLS by accommodating all construct variables that are formulated in hypothesis testing. Fig. 3 shows the value of the results of data processing analysis of each variable.

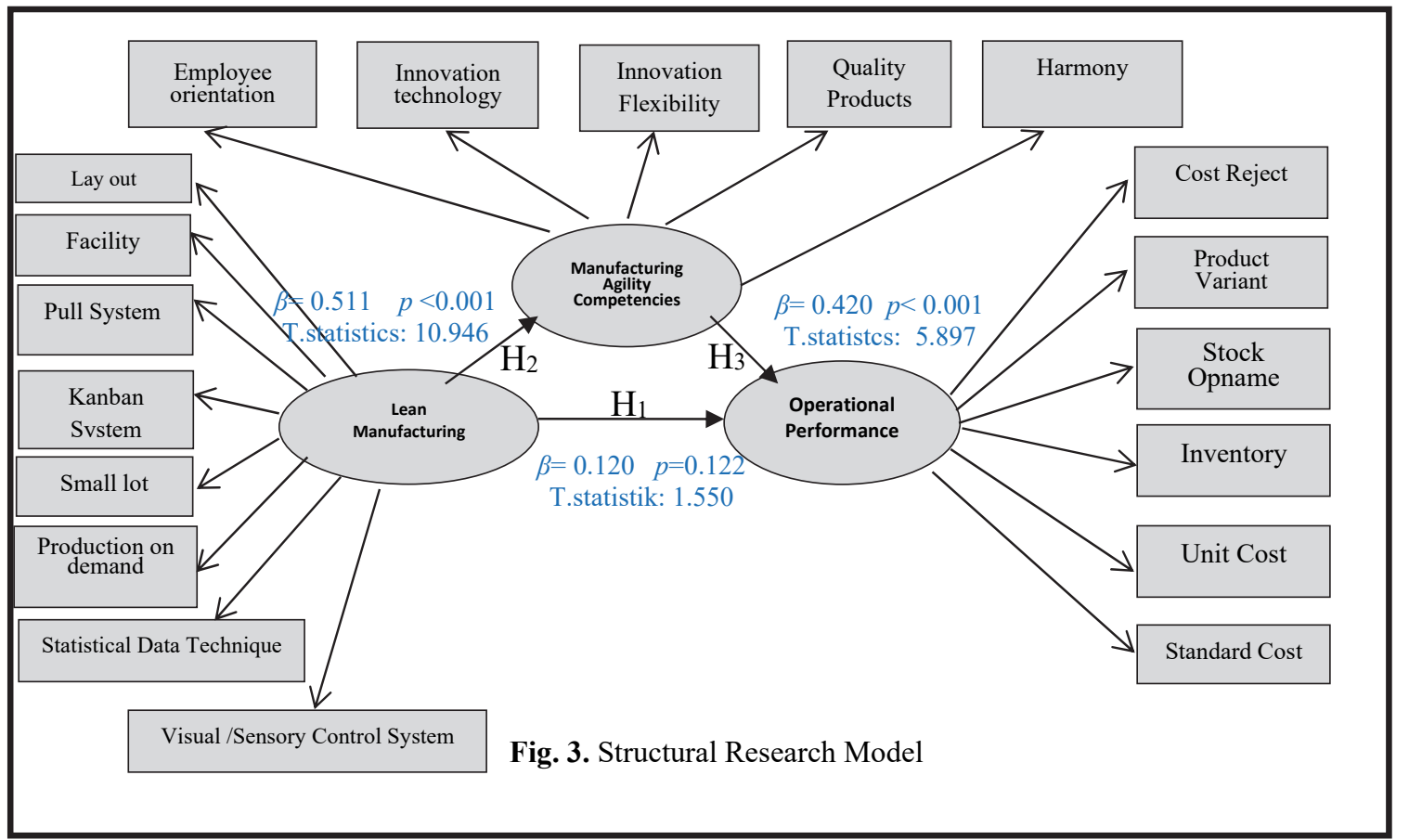


In Fig. 3, all indicators in the outer model analysis have been fulfilled. The figure is equipped with Table 2 to see the variable effect test and Table 3 as a complement to the structural model test. Table 4 shows that this study has met the model fit requirements so that it can be used for further tests.

Table 2

Test of Variable effect

\begin{tabular}{|c|c|c|c|}
\hline \multicolumn{2}{|c|}{ Path Test } & \multirow[t]{2}{*}{$\mathbf{f}^{2}$} & \multirow[t]{2}{*}{ Result } \\
\hline From & to & & \\
\hline LM & MAC & 0.353 & Strong \\
\hline LM & OP & 0.014 & Weak \\
\hline MAC & OP & 0.172 & Sufficient \\
\hline \multirow{3}{*}{ Parameter } & 0.02 & \multirow{3}{*}{\multicolumn{2}{|c|}{$\begin{array}{l}\text { weak effect of exogenous latent variables } \\
\text { sufficient effect of exogenous latent variables } \\
\text { strong effect of exogenous latent variables }\end{array}$}} \\
\hline & 0.15 & & \\
\hline & 0.35 & & \\
\hline
\end{tabular}

Table 3

Construct Cross validated Redundancy

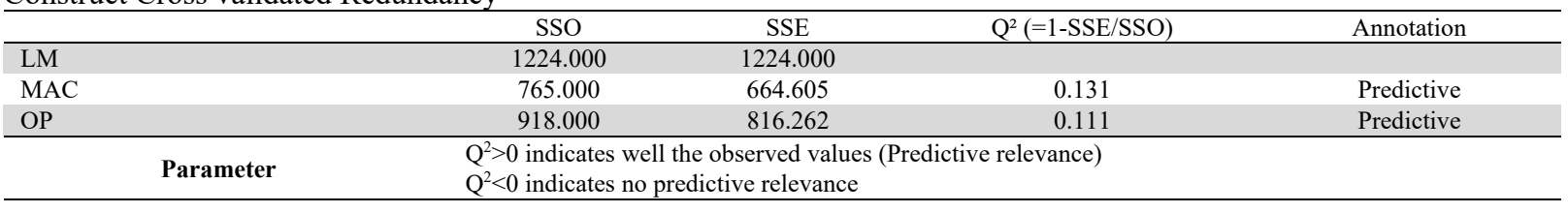

Table 4

Fit test of the model with other parameters

\begin{tabular}{clcccc}
\hline No. & \multicolumn{1}{c}{ Indicator } & Result & Values & Ideal Value & Conclusion \\
\hline 1 & Average Path Coeffisien (APC) & 0.350 & $p<0.001$ & $p<0.05$ & significant \\
2 & Average R Squared (ARS) & 0.252 & $p<0.001$ & significant & $\leq 0.05$ \\
3 & Average Blok VIF (AVIF) & 1,235 & & significant & Large $\geq 0.36$ \\
4 & Tenenhaus GoF & 0.361 & small $\geq 0.1$ & significant \\
\hline
\end{tabular}

\subsection{Hipotesis Testing}

Based on the results of direct or indirect hypothesis testing, the hypothesis is accepted if $\mathrm{p} \leq 0.05$ and has a T.statistic $>$ 1.65 (two-tiled) and $>1.96$ (one-tiled). Based on Fig. 3, the hypothesis (H1) is rejected, while the hypotheses H2, H3, H4 are accepted.

Table 5

Indirect Relationship (Line 2 Pass)

\begin{tabular}{cllccccc}
\hline & Path Analysis & \multirow{2}{*}{ Path Coefficient } & \multirow{2}{*}{ Mean (M) } & \multirow{2}{*}{ Std. Deviation } & Statistics & P \\
\hline From & Mediation & To & & & Values \\
\hline LM & MAC & OP & 0,214 & 0,222 & 0,042 & 5.121 & 0.001 \\
& & Parameter & & & & 1.96 & $<0.05$ \\
\hline
\end{tabular}

Testing the indirect effect or the role of MAC mediation is also proven by the calculations according to Sobel (1982) which shows the value of $\mathrm{t}=5.196$ and the value of $\mathrm{p}<0.001$. Based on the data shown in Fig. 3, Table 5 and the calculation results according to Sobel (1982), the results of the analysis of the research hypothesis are as follows:
$\mathrm{H}_{1}$ : LM has no positive influence on OP.
$\mathrm{H}_{3}$ : MAC has positive effect on OP.
$\mathrm{H}_{2}$ : LM has positive effect on MAC.
$\mathrm{H}_{4}$ : LM has positive effect on OP with MAC mediation.

\section{Discussion, Conclusion and Implication}

Referring to the results of data analysis and references to previous literature, this study seeks to see differences in the results of LM implementation in the non-food industry. The difference in results will be a discussion to be resolved so that it becomes a reference related to the application of LM in the food industry. The relationship between variables will be discussed in the following discussion:

\subsection{The Relationship of $L M$ and $O P$}

\subsubsection{LM practices that have positive effect}

There are several LM practices that support the OP variable in food companies. The analysis is based on the average correlation value between indicators. These practices are:

\section{Small lot production}

Producing in small lots is manifested by producing the product in the required quantity. Many manufacturing industries have felt the success of implementing small lot sizes (Furlan, Vinelli, \& Pont, 2011; Matsui, 2007). LM practices are more focused on the production process by optimizing all the process facilities. Production with a small size allows companies 
to take advantage of process materials that are not too large in volume so they do not take up space. The small lot size which was first pioneered by Matsui, 2007) turned out to give positive results on LM performance against OP in this study. The results of this study are different from the results of previous studies (Engelund et al., 2009; Hallgren \& Olhager, 2009) which successfully applied the LM principle by using large lots in the manufacturing process. According to Engelund et al. (2009) stated that the production of large lots is very suitable for ready-to-eat food products in a predetermined amount so as to shorten the processing and serving time. Meanwhile, the production of large lots was successfully implemented in a combination of LM and AM (Hallgren \& Olhager, 2009). Referring to the research respondents, companies that have a large variety of products with a variable number of requests will choose to produce small lots in anticipation. In this case, the percentage of respondents was $77.78 \%$. The difference in the results of this study with Engelund et al. (2009) and Hallgren and Olhager (2009) lies in the certainty of the number of requests.

\section{Quality Control System (The Use of Statistical Data Techniques)}

In this study, quality control has a positive impact on OP. This research is supported by some of the results of previous studies (Dora \& Gellynck, 2015; Ketokivi \& Schroeder, 2004). Quality control is the most important part of the food industry. Before LM concept was implemented, food companies were forced to implement a strict quality control system. This is related to the regulations that must be met for food safety. Quality control is positively correlated with all OP indicators used in this study. This is in line with research conducted by Dora \& Gellynck (2015) in making it easier for companies to apply the LM concept if it starts from strengthening the quality control system as part of food safety itself. The quality control system will not have a positive impact on OP (Engelund et al., 2009; Simons \& Zokaei, 2005) if its application is concurrent with all LM practices. Implementing it gradually (little by little) will give optimal results.

\subsubsection{LM practices that have negative effect on $O P$}

LM practices that have negative effect on OP in this study are:

\section{Flexible layout for material flow}

The material flow layout design is actually not much different from other manufacturing layouts, and has many positive results on operational performance (Hirano, 2009). In this study, LM practices did not support OP. This is due to 1) most machine installations are permanently installed, making it difficult to move (Cox \& Chicksand, 2005); 2) the process room is provided with a divider; 3) moving employees is not as easy as moving in the non-food manufacturing industry (Engelund et al., 2009); 4) product changeover must be followed by a sanitizing process (Cox \& Chicksand, 2005). The flexible layout that has been the mainstay of LM practice so far has turned out to be a problem in itself if it is implemented in food companies. Non-food companies are not collided with complex regulations such as in the food industry so that material flow engineering must be carried out to get better results (Hirano, 2009). These results illustrate that the definition of Layout flexibility must be flexible to the conditions of the food company.

The use of pull system

Pull system is the most ideal system for the efficiency of all the waste that occurs (Flynn, Sakakibara, \& Schroeder, 1995). In this study, the system turned out to be less supportive of OP. These findings are supported by previous researchers (Krishnamurthy et al., 2000; Spearman \& Zazanis, 1992). The application of pull system in the food industry still leaves its own problems because the system is highly dependent on the following aspects: a) product life: short product life forces pull system (Krishnamurthy et al., 2000); b) product mix: large product variances will complicate the pulling system; c) raw materials: pull system is difficult to implement by companies that have imported raw materials (Spearman \& Zazanis, 1992) and limited natural raw materials are determined by season. Referring to the characteristics of the respondents, there are $87 \%$ of companies that have a product age above 6 months. Based on the data, respondents in this study did not like the pull system. Respondents with a lot of product variance ( $>30)$ were $77.78 \%$. This figure illustrates that pull system is less attractive to respondents. The use of natural raw materials in this study was only around $15.03 \%$. This figure shows the respondent's interest in pull system because natural raw materials have a tendency towards a short product life.

\section{Production Facilities}

The production facilities in this study include all facilities that are used to smooth the production process. The results of this study were supported by previous researchers (Cox \& Chicksand, 2005). The results of this study contradict what was found by Hirano (2009). Production facilities must support the flexibility of material flow and the ease of moving machines by engineering adjacent production processes (Hirano, 2009). Production facilities include not only machinery and equipment but also the treatment of employees who want to enter or leave the production room. This will be a problem in itself for companies that are still low-scale. Keeping all equipment and employees free of physical, chemical, microbiological contaminants continues to be a complexity in the food industry process. The costs for this condition are not low, so only large-scale companies are able to implement.

\section{Visual/Sensory Control System}

In this study, the visual / sensory control system has not had a positive impact on OP. These results are consistent with the findings of Brosnan \& Sun (2004) who experienced difficulties in measuring the quality of food products in the form of "shape, smell and taste". The results of this study are very different from what has been researched by previous researchers. 
Visual/sensory control is a quality control that has an impact on the implementation of LM (Ketokivi \& Schroeder, 2004) which still relies on visuals or the five senses. The visual/sensory control system performed at the time of the instrument test has not been able to replace the role of the visual test (Brosnan \& Sun, 2004) although there are several tests that have been able to use laboratory instruments or detection tools. Another sensory test that does not have a detection tool is the shape, smell, taste of a product (Brosnan \& Sun, 2004). Food companies try to make standard standards for organoleptic tests by using a device that has a size and unit so that it is not based on perception. The application of the visual/sensory control system is largely determined by the conditions and circumstances of the food company (Dora \& Gellynck, 2015). There are two basic factors that make companies accept and reject the control system. The first factor is the composition of the product formula. Food companies that have a natural composition of raw materials will tend to accept visual / sensory control systems. This is very contradictory to the use of artificial / engineered raw materials. Natural raw materials will find it difficult to get the same standard quality from time to time. Engineered products tend to have the exact same quality over time. The second factor is Certification. The number of food certifications requires clear and measurable standard references. This condition will make companies tend to reject measurements based on the five senses because parameters based on perceptions are difficult to maintain quality within a certain period of time (Brosnan \& Sun, 2004). Referring to the characteristics of the respondents, the companies that want this control system are $29.41 \%$ when seen from the number of certifications, namely only 1 certification. The rest is $70.59 \%$ who do not like this control system $(\geq 2$ certificates). The use of natural raw materials in this study was around $15.03 \%$. This figure shows the range of companies that like visual/sensory control systems. The rest didn't like the control system. The description above shows that the visual/sensory control system is less preferred by food companies.

\subsection{The Effect of LM on MAC}

Referring to the research data analysis, the two variables have a positive effect. The important findings in this research are: first, the pull system and visual/sensory control system were successfully adopted by the innovation; second, MAC practices that play the most role in improving LM practices are quality systems (innovation); third, the application of LM in the food industry must separate the quality system from LM practices; fourth, the layout (Flexible Lay out) has not been able to be utilized by MAC in this study. The following is a complete discussion of these indicators:

\subsubsection{LM Practices that Have Positive Effect on MAC}

LM practices that have a positive effect on MAC in this study include:

\section{Small Lot Production}

In this study, production with small lots has a positive impact on MAC performance. This proves that small lot sizes are optimally utilized in the product mix flexibility process (Krishnamurthy et al., 2000) and the quality control process (Dora \& Gellynck, 2015). These findings confirm that LM practices are positively correlated with increased activity in MAC, especially in terms of product innovation that does not hinder the flexibility of the production process (Gunasekaran, 1998). These findings reinforce the results of previous research related to the application of small lot sizes in the use of technology for innovation (Gunasekaran, 1999), harmonious relationships between suppliers and consumers (Gunasekaran, 1999) and the effect of small lots on employee orientation towards quality (Could, 1997).

\section{Visual/Sensory Control System}

The use of visua/sensory control systems was initially less supportive of increasing OP. In this research, LM practices are in fact synergized well with MAC practices, namely: Knowledge, R\&D and external relations (suppliers and consumers). The findings of this study are similar to the research conducted by Brosnan \& Sun (2004) which emphasizes the visual/sensory control system as both strength and uniqueness in the process. MAC responds to the visual/ sensory control system by offering a product with natural ingredients. Its unique differentiation is that it is very difficult to condition products made from natural ingredients due to the stability of product quality in the long term. The visual/ sensory control system will attempt to equalize perceived quality with its suppliers and consumers. This is difficult to do because quality control only relies on the five senses related to product quality in the form of shape, color, smell, taste. The similarity of perceptions will create harmony in itself. Harmony will emerge with the involvement of the heart and empathy if it is able to last for a long time (Gunasekaran, 1999).

\section{Statistical Data Techniques}

In this study, statistical data techniques have a positive correlation with MAC practices, namely employee orientation towards food quality, use of technology for innovation, and innovation that does not hinder flexibility. This finding is supported by previous researchers (Liu, Lin, \& Shu, 2017) regarding the use of statistical data techniques to measure the level of employee orientation for measuring the validity of employee performance against quality. Statistical data techniques in use for technology and innovation have received support from previous researchers (Dubickis \& GaileSarkane, 2015). The use of statistical data for innovations that do not hinder flexibility is also evident in the findings of this study. This result is supported by the findings of previous researchers (Telukdarie et al., 2018).

\section{Pull System}

Pull system that had no impact on operational performance turned out to be well responded to by MAC. The findings in this study are supported by previous studies that have observed the tensile system (Krishnamurthy et al., 2000). This system 
will have a positive correlation for companies that have products with a short life time. It will be successful if the company is forced to do it and there is no other alternative besides pull system because it involves the character of the product. Flexibility as a trait of MAC is hampered by coercive conditions. The role of innovation has succeeded in making the pull system play a role in MAC activity. Pull system is rarely successful in the food industry. This system in production is identical to the Just In Time process which has zero tolerance to Mistake, so it will be difficult to make repairs or rework in food products because food products cannot be repaired (King et al., 2008). The system will be difficult for food companies to do if there is a high surge in demand while the company's capacity cannot meet the specified time limit.

\subsubsection{LM Practices which Negatively Affect on MAC}

In this study, the LM practice that does not have a positive effect was the layout (flexible layout and production facilities). This finding is supported by previous researchers conducted in the food industry (Dora \& Gellynck, 2015). Referring to the results of data analysis and previous literature reviews, imposing flexibility in layout according to the definition of LM is generally impossibility when applied in the food industry. Imposing flexibility according to LM so far will put the distribution permit of a food product at risk so that layout flexibility must evolve if applied in the processing industry. This research examines the flexibility desired by food processing companies, especially food. The flexibility of the food industry is synonymous with an activity to reduce/eliminate waste in the form of time in the process without the potential for product contamination. Controlling the sanitation process with a sorting strategy that reduces sanitation time already reflects general flexibility in the food industry.

\subsection{The Effect of $M A C$ on $O P$}

In the results of data analysis, MAC practice has a positive effect on OP. Here is a further discussion.

\section{Utilization of Technology for Innovation}

Utilization of existing technology means optimizing machines and equipment as much as possible. Innovation is not only oriented towards new product innovation but comprehensive innovation which includes innovation to get the ideal machine setting so that it is more efficient and effective in its use. This finding is supported by previous research related to innovation and technology (Dubickis \& Gaile-Sarkane, 2015).

\section{Innovations That don't Get in the Way of Flexibility}

This research focuses more on the use of innovation resources to eliminate the cost of damage, create new markets and improve the quality of food products which include innovation in stability (product life), taste innovation, and nutritional value innovation. This study confirms the findings of Telukdarie et al. (2018) who use limited resources to create more valuable innovations.

\section{External Relations (Suppliers and Consumers)}

Upholding harmony between companies, suppliers and consumers is the practice of MAC activities in this study. Companies must be sensitive to the changing nature and willingness of consumers who change over time. Companies must be able to provide services to consumer desires by providing competitive prices, quality products, and always providing service (customer service) to complaints and aspirations conveyed by customers/consumers. MAC practices that do not contribute positively to OP are reliable HR (multi-talented employees and employees with high loyalty). Reliable human resources do not contribute to OP. This contradicts the results of previous studies. All of these researchers agree that reliable human resources are the key to successful performance. Multi-talented employees are less supportive of improving operational performance in this study. This is due to the routine work of the food company which involves many people with a relatively low level of work difficulty and only focuses on one area. Similar results were also carried out by (Dora \& Gellynck, 2015). This condition is very opposite in the effort to increase talent. Employees' talents or talents will not be honed and contribute positively if they are placed in one area. Talent appears from various sides and sometimes companies prioritize attitude over talent.

\subsection{The Role of Mediation}

In this study, the role of MAC is successful in increasing the effect of LM on OP. The increase occurres in LM practices which previously have no direct positive effect. LM practices are:

\section{Visual/Sensory Control System}

The visual/sensory control system, which is initially disliked by most food companies due to its standard reference (Brosnan \& Sun, 2004), is successfully adopted by MAC to become a product with full innovation with the use of technology. The healthy lifestyle of consumers must be captured by making natural products without synthetic ingredients in their composition. The visual/sensory control system has been successfully adopted by MAC into a control system that is correlated with other tests that have standard standards. The visual/sensory control system is correlated with stability tests, contaminant level tests (metal and microbiology), content composition tests, nutritional value tests, etc. The correlation is done so that the visual/sensory control system has a standard standard even though the process is indirect. 
This LM practice has not had a direct positive impact on OP. The use of pull system adopted by MAC is a strategy that has a positive impact on OP. MAC always responds quickly to potential strengths and opportunities. The system is only effective for short-lived products. This is used by MAC through product innovation with natural raw materials as a differentiator from other products. The system has to be forced in order to succeed. A solution must be sought for any consequence so that the pull system can have optimal benefits. Product innovation with natural composition will force pull system to run even with coercion.

\section{Conclusion and Suggestion}

LM practices do not have a direct positive effect on OP. Meanwhile, LM practices have succeeded in providing a positive effect on OP after being mediated by MAC. MAC has successfully adopted the pull system and visual/sensory control system through innovations that have an effect on OP. In this study, MAC has not been able to adopt LM practices such as layout (flexible layout and production facilities). This becomes a criticism of the layout definition which has been the practice of LM so far. Flexibility does not only refer to practices and characteristics, but also applies to definitions so that LM practices can be accepted in all industrial sectors. The application of LM practices in the food industry should separate quality control systems from LM practices. The quality control system is positioned independently and LM practices gradually follow the will of the quality control system. This is to avoid confusion in its implementation. The author provides two suggestions. First, research samples to be more specific related to food companies based on product specifications (expiration period, raw material composition), company reputation, company turnover, categories and types of food products in order to obtain research results that reflect the characteristics of the object under study. Second, the visual/sensory control system that many food companies do not like which have artificial/non-natural raw materials is to be further innovated in order to create food products that have a unique appeal by using natural raw materials as the strength of their products.

\section{References}

Almahamid, S., Awwad, A., \& Arthur C. McAdam. (2010). Effects of organizational agility and knowledge sharing on competitive advantage : an empirical study in Jordan. Industrial Marketing Management, 27(3), 387.

Bag, S., Gupta, S., \& Telukdarie, A. (2018). Importance of innovation and flexibility in configuring supply network sustainability. Benchmarking, 25(9), 3951-3985. https://doi.org/10.1108/BIJ-06-2017-0132

Brosnan, T., \& Sun, D. W. (2004). Improving quality inspection of food products by computer vision - A review. Journal of Food Engineering, 61(1 SPEC.), 3-16. https://doi.org/10.1016/S0260-8774(03)00183-3

Could, P. (1997). What is agility? Manufacturing Engineer.

Cox, A., \& Chicksand, D. (2005). The limits of lean management thinking: Multiple retailers and food and farming supply chains. European Management Journal. https://doi.org/10.1016/j.emj.2005.10.010

Danilovic, M., \& Leisner, P. (2007). Analyzing core competence and core products for developing agile and adaptaptable corporation. Proceedings of the 9th International DSM Conference.

Dora, M., \& Gellynck, X. (2015). House of lean for food processing SMEs. Trends in Food Science and Technology, 44(2), 272-281. https://doi.org/10.1016/j.tifs.2015.03.008

Dubickis, M., \& Gaile-Sarkane, E. (2015). Perspectives on Innovation and Technology Transfer. Procedia - Social and Behavioral Sciences. https://doi.org/10.1016/j.sbspro.2015.11.512

Engelund, E. H., Breum, G., \& Friis, A. (2009). Optimisation of large-scale food production using Lean Manufacturing principles. Journal of Foodservice. https://doi.org/10.1111/j.1748-0159.2008.00109.x

Flynn, B. B., Sakakibara, S., \& Schroeder, R. G. (1995). Relationship Between JIT and TQM: Practices and Performance. Academy of Management Journal. https://doi.org/10.5465/256860

Fornell, C., \& Larcker, D. F. (1981). Evaluating Structural Equation Models with Unobservable Variables and Measurement Error. Journal of Marketing Research. https://doi.org/10.2307/3151312

Furlan, A., Vinelli, A., \& Pont, G. D. (2011). Complementarity and lean manufacturing bundles: An empirical analysis. International Journal of Operations and Production Management. https://doi.org/10.1108/01443571111153067

Ghozali. (2011). Aplikasi Analisis Multivariate dengan Program SPSS. Jurnal Ilmiah Universitas Pandanaran. https://doi.org/10.1177/107049659800700202

Gilgeous, V., \& Parveen, K. (2001). Core competency requirements for manufacturing effectiveness. Integrated Manufacturing Systems. https://doi.org/10.1108/09576060110391183

Gunasekaran, A. (1998). Agile manufacturing: Enablers and an implementation framework. International Journal of Production Research, 36(5), 1223-1247. https://doi.org/10.1080/002075498193291

Gunasekaran, A. (1999). Agile manufacturing: a framework for research and development. International Journal of Production Economics. https://oi.org/10.1016/S0925-5273(98)00222-9

Hallgren, M., \& Olhager, J. (2009). Lean and agile manufacturing: External and internal drivers and performance outcomes. International Journal of Operations and Production Management. https://doi.org/10.1108/01443570910993456

Hirano, H. (2009). JIT Implementation Manual -- The Complete Guide to Just-In-Time Manufacturing. In JIT Implementation Manual -- The Complete Guide to Just-In-Time Manufacturing. https://doi.org/10.1201/b10229

Jabbour, C. J. C., De Sousa Jabbour, A. B. L., Govindan, K., Teixeira, A. A., \& De Souza Freitas, W. R. (2013). Environmental management and operational performance in automotive companies in Brazil: The role of human 
resource management and lean manufacturing. Journal of Cleaner Production. https://doi.org/10.1016/j.jclepro.2012.07.010

Jin-Hai, li, Anderson, A. R., \& Harrison, R. T. (2003). The evolution of agile manufacturing. Business Process Management Journal. https://doi.org/10.1108/14637150310468380

Ketokivi, M., \& Schroeder, R. (2004). Manufacturing practices, strategic fit and performance. International Journal of Operations \& Production Management. https://doi.org/10.1108/01443570410514876

King, P. L., Kroeger, D. R., Foster, J. B., Williams, N., \& Proctor, W. (2008). Making CEREAL not CARS. Industrial Engineer.

Krafcik, J. F. (1988). Triumph of the lean production system. Sloan Management Review. https://doi.org/10.1108/01443570911005992

Krishnamurthy, A., Suri, R., \& Vernon, M. (2000, May). Push can perform better than pull for flexible manufacturing systems with multiple products. In Industrial Engineering Research 2000 Conference Proceedings.

Liu, C., Lin, B., \& Shu, W. (2017). Employee quality, monitoring environment and internal control. China Journal of Accounting Research. https://doi.org/10.1016/j.cjar.2016.12.002

Mahoney, J. T., \& Pandian, J. R. (1992). The resource-based view within the conversation of strategic management. Strategic Management Journal. https://doi.org/10.1002/smj.4250130505

Matsui, Y. (2007). An empirical analysis of just-in-time production in Japanese manufacturing companies. International Journal of Production Economics. https://doi.org/10.1016/j.ijpe.2006.12.035

Moori, R. G., Pescarmona, A., \& Kimura, H. (2013). Lean Manufacturing and Business Performance in Brazilian Firms. Journal of Operations and Supply Chain Management. https://doi.org/10.12660/joscmv6n1p91-105

Ohno, T. (1978). Tovota Production System- Beyond Large-Scale Production. Journal of Chemical Information and Modeling. https://doi.org/10.1017/CBO9781107415324.004

Osterman, \& Paul. (1994). How common is workplace transformation and who adopts it? Industrial \& Labor Relations Review.

Prahalad, C. K., \& Hamel, G. (1990). The core competencies of the corporation. Harvard Business Review. https://doi.org/100-003-757

Shah, R., \& Ward, P. T. (2003). Lean manufacturing: Context, practice bundles, and performance. Journal of Operations Management. https://doi.org/10.1016/S0272-6963(02)00108-0

Simons, D., \& Zokaei, K. (2005). Application of lean paradigm in red meat processing. British Food Journal, 107(4), 192211. https://doi.org/10.1108/00070700510589495

Sobel, M. E. (1982). Asymptotic Confidence Intervals for Indirect Effects in Structural Equation Models. Sociological Methodology. https://doi.org/10.2307/270723

Spear, S., Bowen, H. K., \& Ninc, a M. Y. (1999). Decoding the DNA of the Toyota Production System. Harvard Business Review.

Spearman, M. L., \& Zazanis, M. A. (1992). Push and pull production systems. Issues and comparisons. Operations Research. https://doi.org/10.1287/opre.40.3.521

Sud-on, P., Abareshi, A., \& Pittayachawan, S. (2014). Agility enablers, capabilities and performance. International Conference on Logistics Systems and Management, (February 2015). https://doi.org/10.13140/2.1.3569.4884

Sugimori, Y., Kusunoki, K., Cho, F., \& UCHIKAWA, S. (1977). Toyota production system and kanban system materialization of just-in-time and respect-for-human system. The International Journal of Production Research, 15(6), 553-564.

Telukdarie, A., Buhulaiga, E., Bag, S., Gupta, S., \& Luo, Z. (2018). Industry 4.0 implementation for multinationals. Process Safety and Environmental Protection. https://doi.org/10.1016/j.psep.2018.06.030

Uhrin, Á., Bruque-Cámara, S., \& Moyano-Fuentes, J. (2017). Lean production, workforce development and operational performance. Management Decision, 55(1), 103-118. https://doi.org/10.1108/MD-05-2016-0281

Wernerfelt, B. (1984). A resource-based view of the firm. Strategic Management Journal. https://doi.org/10.1002/smj.4250050207

Womack, J. P., \& Jones, D. T. (1994). From Lean Production to the Lean Enterprise. Harvard Business Review.

Womack, J. P., Jones, D. T., \& Roos, D. (1990). The Machine that Changed the World: The Story of Lean Production. World. https://doi.org/10.1016/0024-6301(92)90400-V

Wu, Y. C. (2003). Lean manufacturing: A perspective of lean suppliers. International Journal of Operations and Production Management. https://doi.org/10.1108/01443570310501880

Zokaei, K., \& Simons, D. (2006). Performance improvements through implementation of lean practices: A study of the U.K. Red Meat Industry. International Food and Agribusiness Management Review.

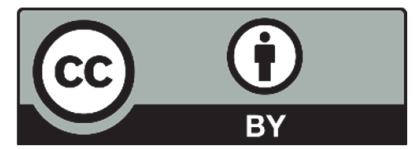

(C) 2021 by the authors; licensee Growing Science, Canada. This is an open access article distributed under the terms and conditions of the Creative Commons Attribution (CC-BY) license (http://creativecommons.org/licenses/by/4.0/). 